\title{
Reconstruction of Large-Scale Atmospheric Circulation and Data Assimilation in Paleoclimatology
}

\author{
M. Widmann, J.M. Jones and H. von StoRch \\ GKSS Research Centre, Geesthacht, Germany; widmann@gkss.de
}

Quantitative estimates of natural climate variability are essential for assessing human influence on climate. On long timescales they are derived from paleoclimatic proxy data, such as tree rings and varved sediments (e.g. DEKLIM-PROSIMUL), corals (e.g. DEKLIM-Corclim) and ice cores (e.g. DEKLIM-RESPIC). Past climates can also be simulated using numerical climate models (e.g. DEKLIMGHOST, CLIMCYC, and the newly funded MIDHOL). Consistency tests between empirical and simulated climate estimates (e.g. Jones et al. 1998, Zorita et al. 2004) can reduce uncertainties, and contribute to the validation and improvement of climate models. In the DATUN (Data Assimilation Through Upscaling and Nudging) project, a new approach has been developed in which data and models are not compared but used jointly to provide estimates for past climate (von Storch et al. 2000, Jones and Widmann 2004). DATUN is a data assimilation technique that is tailored towards applications in paleoclimatology. It consists of an upscaling step, in which large-scale circulation is derived statistically from empirical data, followed by an assimilation step in which the atmospheric states in a climate model are forced to be consistent with the empirical estimates. Here we present an example for upscaling and test experiments with the assimilation method.

DATUN will be tested on instrumental data, before being applied to proxy data. We will force the ECHAM4 General Circulation Model (GCM) for the $20^{\text {th }}$ century towards monthly or longer means of the amplitudes of the dominant circulation modes in the Northern and Southern Hemispheres, the Arctic and Antarctic Oscillations (AO, AAO), and then compare actual and simulated climate. Unlike in the Northern Hemisphere, gridded datasets for the Southern Hemisphere only extend back to the middle of the $20^{\text {th }}$

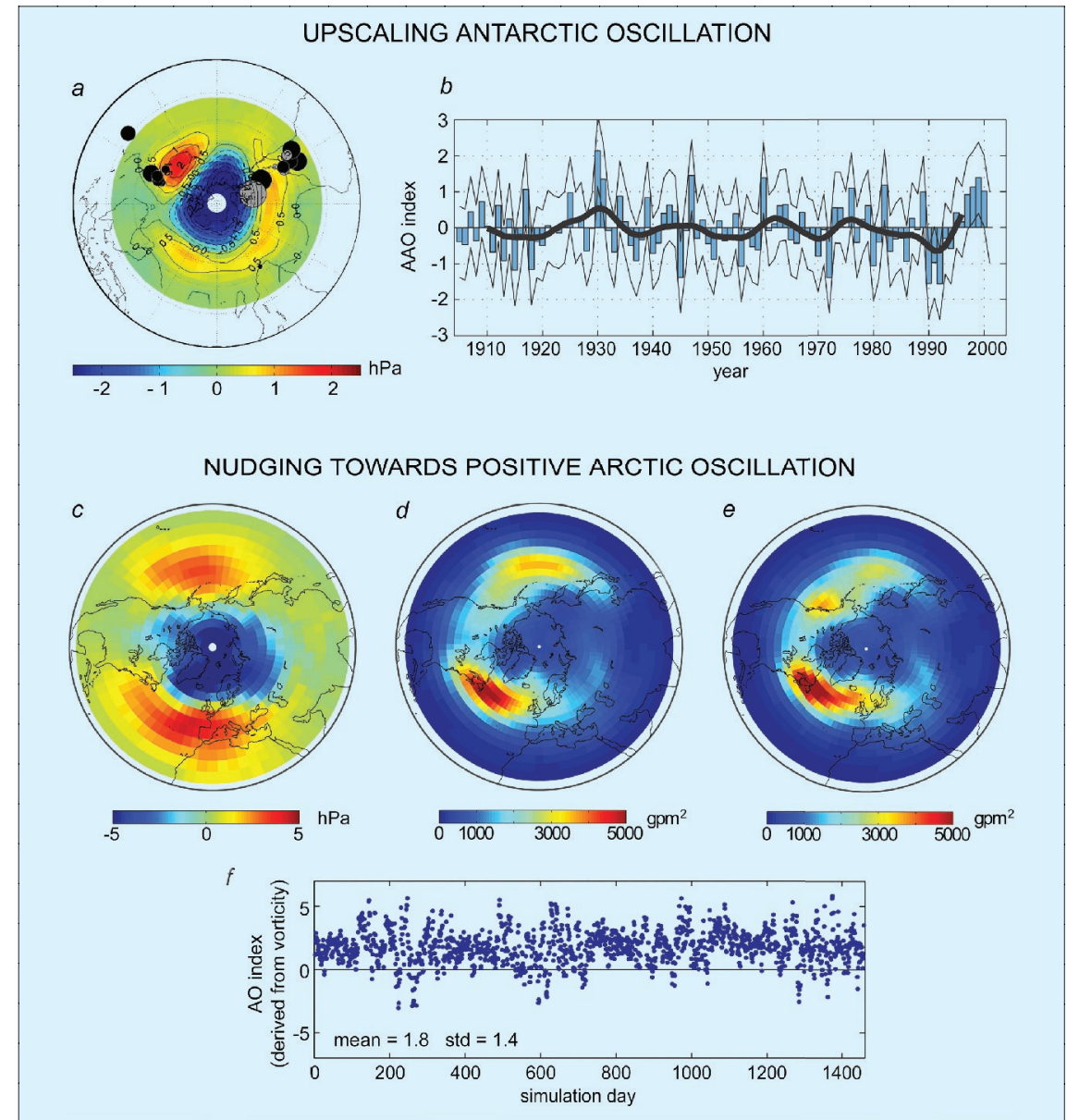

Fig. 1: (a) The MAM Antarctic Oscillation pattern (EOF1 of detrended ERA4O SLP) and the locations and statistical weights of the standardized station pressure records used to reconstruct the AAOI. Colors and isolines show the pressure change in hPa for AAOI + 1. The station regression weights are dimensionless and are given by the circle area. The grey circles denote negative values; the black circles positive values. Based on validation with independent data, $50 \%$ of the variability of the true AAO (from the ERA40 reanalysis) is captured by the reconstruction. (b) The reconstructed MAMAAOI. Bars show the reconstruction and the solid black line is the 11-year filtered mean using a Hamming window. The thin lines show the 95\% confidence interval. ERA40 data kindly provided by the ECMWF, station data by Phil Jones. (c) The AO pattern in January (EOF1 of detrended NCEP Reanalysis SLP). The pressure change for a positive AOI of one standard deviation is shown. (d) Stormtracks in January (2.5d-6d filtered 500 hPa geopot. height) in a control run without nudging. (e) As 1d but in a run nudged towards a positive AO state. (f) Amplitudes of the AO signal in $850 \mathrm{hPa}$ vorticity in a run nudged towards a positive AO state. NCEP reanalysis kindly provided by NCEP-NCAR. We thank Reiner Schnur and Ingo Kirchner for support with implementing pattern nudging into ECHAM4.

century. We have thus reconstructed the strength of the AAO, the Antarctic Oscillation Index (AAOI), from long pressure measurements using a principal component regression method. Similar upscaling methods have been used to reconstruct numerous climate features from proxy data, including global- to regional-scale temperatures and the strength of atmospheric circulation modes (for an overview see Jones and Mann 2004). Our work builds on the station-based reconstruction of the Austral Summer (November-January) AAOI of Jones and Widmann (2003), who also produced a longer reconstruction using tree-ring width chronologies. The station-based reconstructions have now been extended to cover the four standard seasons. An example for Austral Autumn (March-May) is shown in Fig. 1a/b.

Assimilation simulations complement equilibrium runs and experiments with temporally varying 
forcings (for an overview see, e.g. Widmann and Tett 2003). Because of internal variability, the forcing factors do not completely determine the state of the system, and thus a transient forced run will yield only one of many possible realizations of the climate that are consistent with the forcing. Assimilation simulations attempt to also include part of the historic internally generated variability and compensate for model deficiencies. Data assimilation into atmospheric GCMs has been operationally employed for numerical weather prediction and atmospheric reanalyses using sophisticated methods, as well as for process studies and model validation using the simpler nudging method, which directly forces the model states towards prescribed target values. To adapt nudging to paleoclimatic applications, where the climate estimated from proxy data is relatively uncertain, DATUN was developed. The first step is the estimation of large-scale climate states through upscaling, as described above. The second step will employ a newly developed pattern nudging technique to nudge the model state towards the estimated large-scale states, without directly affecting components of the climate state that are not constrained by proxy data, and without suppressing synoptic-scale variability.

In test experiments, the ECHAM4 atmospheric GCM was nudged towards constant target amplitudes of the AO. Instead of directly nudging the model SLP towards the AO pattern (Fig. 1c), the relative vorticity of the wind field was nudged throughout the lower half of the troposphere towards the AO vorticity signal (not shown), which was defined by regression maps (Widmann 2004). The amplitudes of the vorticity pattern can be modified as desired (Fig. 1f), the SLP response to the nudging shows the $A O$ structure and the specified amplitude (not shown), and stormtracks are modified in a physically plausible way without being suppressed (Fig. 1 d/e). Experiments using a coupled atmosphere-ocean GCM and historic values of largescale anomalies are in preparation.

\section{REFERENCES}

Jones, J. M. and Widmann, M., 2003: Instrumentand tree-ring-based estimates of the Antarctic Oscillation. J. Climate 16: 3511-3524.

Jones, J. M. and Widmann, M., 2004: Reconstructing large-scale variability from palaeoclimatic evidence by means of Data Assimilation Through Upscaling and Nudging (DATUN). In: Fischer, $H_{\text {., }}$ Kumke, T., Lohmann, G., Flöser, G., Miller, H., von Storch, H., and Negendank, J. F. W. (eds.), 2004: The KIHZ project: towards a synthesis of Holocene proxy data and climate models. Springer, Heidelberg, Berlin, New York. ISSN 1437-028X.

Jones, P. D. and Mann, M. E., 2004: Climate over Past Millennia. Reviews of Geophysics, 42: RG2002/ 2004

Widmann, M., 2004: One-dimensional CCA and SVD, and their relationship to regression maps. J. Climate, in revision.

Widmann, M. and Tett, S. F. B., 2003: Simulating the climate of the Last Millennium.PAGES Newsletter: 11(2/3), 21-23

For full references please consult:

www.pages-igbp.org/products/newsletters/ref2004_2.html

\title{
Solar Variability and Holocene Climate: Evidence from Radiocarbon, Tree-Ring Proxies and Climate System Modeling
}

\author{
B. Kromer ${ }^{1}$, M. Claussen $^{2}$, N. Latuske ${ }^{1}$, M. LüKen ${ }^{2}$, S. Remmele ${ }^{1,4}$ and G. Schleser ${ }^{3}$ \\ ${ }^{1}$ Heidelberger Akademie der Wissenschaften, Institut für Umweltphysik, INF 229, 69120 Heidelberg; bernd.kromer@iup.uni-heidelberg.de \\ 2Potsdam Institut für Klimaforschung, Telegrafenberg A31, 14473 Potsdam \\ Institut für Chemie und Dynamik der Geosphäre, Forschungszentrum Jülich GmbH, 52425 Jülich, \\ ${ }^{4}$ Institut für Botanik-210, Universität Hohenheim, 70595 Stuttgart, Germany
}

Solar forcing of climate is a longstanding unresolved issue. Eddy (1976) was among the first to postulate a link between a widespread cooling event and a low level of solar activity, suggested by the absence of sunspots in the $17^{\text {th }}$ century (Maunder minimum). Prior to visual observations of solar activity, only cosmogenic isotopes, such as ${ }^{14} \mathrm{C},{ }^{10} \mathrm{Be}$ and ${ }^{36} \mathrm{Cl}$, preserved in well dated archives, provide proxy information for solar heliomagnetic activity. Their production rate depends on the shielding of the Earth by the magnetic field around the Earth, i.e. the superposition of the Earth's dipole moment and the solar wind (Masarik and Beer 1999).

In our project within DEKLIM, we focus on the reconstruction of solar activity using the decadal to century-scale fluctuations in

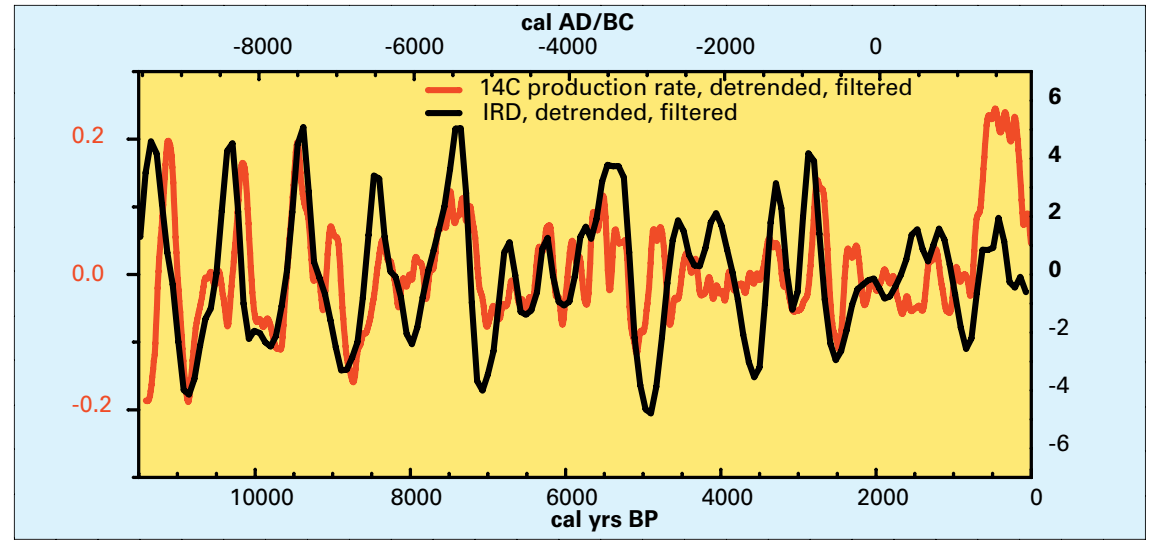

Fig. 1: Changes in ${ }^{14} \mathrm{C}$ production rate (difference to long term trend, unit is atoms $/ \mathrm{cm}^{2} / \mathrm{sec}$ ) compared to the percentage of hematite stained grains in North Atlantic cores MC52, V29191, V2381 (for details and locations see Bond et al. 2001). The ${ }^{14} \mathrm{C}$ production has been calculated using an Oeschger-Siegenthaler carbon box model, from $\Delta^{14} \mathrm{C}$ in IntCal98 (Stuiver et al. 1998) and new extensions. The data sets are low-pass filtered, and detrended to remove the longterm trend. Cooling events throughout the Holocene are coincident with intervals of low solar activity (high ${ }^{14} \mathrm{C}$ production rate).

atmospheric ${ }^{14} \mathrm{C}$ levels of the past 12,000 years, and investigate climate proxies in tree-rings during intervals of quiet and active sun.
The ${ }^{14} \mathrm{C}$ level in the past is obtained from high-precision ${ }^{14} \mathrm{C}$ analyses of decadal tree-ring sections, and ${ }^{14} \mathrm{C}$ production is then calculated 